\title{
Adherence to Secondary Stroke Prevention in Children with Sickle Cell Anemia: Family and Child Perspectives
}

Lydia Boateng1', Eve Puffer ${ }^{2}$, Taryn Allen², Melanie Bonner ${ }^{2}$ and Courtney D Thornburg ${ }^{1 *}$

${ }^{1}$ Division of Pediatric Hematology/Oncology, Duke University Medical Center, USA

${ }^{2}$ Department of Psychiatry and Behavioral Sciences, Duke University Medical Center, USA

\begin{abstract}
Children with sickle cell anemia and primary stroke are at high risk of secondary stroke. Transfusions reduce but do not eliminate this risk and results in iron overload. Hydroxy urea in combination with phlebotomy is an alternative. We conducted semi-structured interview based on the Health Belief Model to examine factors influencing adherence to secondary stroke prevention. Participants were 14 caregivers of children with history of stroke and 12 of their children, ages 8 to 17 years. Barriers to adherence included high frequency and length of clinic visits, disruption of school and work, and lack of resources. Facilitators included health benefits of therapy, social support systems, medication reminders, and positive clinic experiences. Caregivers and children reported a preference for hydroxyl urea over transfusions, as they perceived fewer barriers and equivalent benefits. Healthcare providers should work with families to preemptively identify and address barriers to secondary stroke prevention which may compromise care.
\end{abstract}

Keywords: Sickle cell anemia; Stroke; Family perceptions; Adherence

Abbreviations: SCA: Sickle Cell Anemia; HBM: Health Belief Model

\section{Introduction}

Children with sickle cell anemia (SCA) and primary stroke are at high risk of recurrent (secondary) stroke. Overt strokes occur in $11 \%$ of patients with homozygous hemoglobin SS disease, SCA, before age 20 [1]. Secondary stroke prevention includes regular blood transfusion therapy to suppress synthesis of hemoglobin S. Without transfusions, approximately $67 \%$ will have secondary overt stroke. Even with regular transfusions [1-3], the rate remains at 2.2-6.4 per 100 patient-years. Transfusions are associated with substantial morbidity including autoand alloimmunization, catheter-related infections, and iron overload, requiring lifelong iron chelation therapy [4].

We previously reported the use of hydroxyl urea and phlebotomy as an alternative to chronic transfusion therapy to reduce stroke risk and improve management of iron overload [5-7]. Results showed a secondary stroke rate of 4.7 per 100 patient-years and reduced iron overload [7]. The randomized clinic trial Stroke with Transfusions Changing to Hydroxyurea (SWiTCH, NCT00122980) was designed to compare transfusions with hydroxyurea. The study was terminated early, however, based on interim analyses showing non inferiority for stroke but equivalent liver iron content [8]. Thus, transfusion remains the standard of care. Nonetheless, some patients are still prescribed hydroxyl urea if transfusions are not accepted by the family or are not feasible due to multiple allo and/or auto antibodies, severe iron overload or allergy to chelators.

Outcome of both transfusion/chelation and hydroxyl urea/ phlebotomy for secondary stroke prevention is highly dependent on attending clinic visits and adhering to medication regimens. Overall, adherence with therapy for chronic conditions is suboptimal. Secondary stroke prevention with hydroxyl urea depends on attending clinic appointments for hydroxyl urea monitoring and phlebotomy and taking hydroxyl urea at home. Reported adherence rates for clinic appointment attendance are approximately $80 \%[9,10]$. Reported adherence with taking hydroxyl urea varies from 30-90\% [9-12], with low adherence associated with poor clinical outcomes in patients with a history stroke
[7]. Barriers to hydroxyl urea adherence in patients without a history of stroke are well described $[9,12-17]$. Adherence to phlebotomy has not been reported to be a problem $[7,18]$. Secondary stroke prevention with transfusion depends on attending clinic appointments for transfusion and chelation monitoring and taking oral chelation at home. Adherence with transfusion therapy is also sub optimal. In the SWiTCH trial, 1 out of every 66 subjects was deemed non-adherent with transfusions. In a survey of transfusion practices for primary stroke prevention, $30 \%$ of children had at least one transfusion given later than prescribed [19]. Adherence with iron chelation is also problematic [20-22]

The purpose of this study was to examine the factors related to adherence by assessing costs, benefits, and challenges from the perspectives of the children and caregivers. This builds upon previous literature in that this study compares barriers and facilitators to adherence across treatments, including participants who have switched from one treatment to another. We have used the Health Belief Model (HBM; Figure 1) to frame our exploration of these issues.

The HBM provides a framework to understand both treatment preferences and associated health behaviors [23]; health behaviors are influenced by a person's perception of disease severity and susceptibility, the benefits of the prevention behavior, and barriers toward action. Individual perceptions are moderated by socio psychological factors and demographics, as well as "cues to action" which include knowledge about the disease and messages one receives about the health behavior In the context of stroke prevention, the likelihood that a child will adhere to secondary stroke prevention depends on the perception

*Corresponding author: Courtney Thornburg, Department of Psychiatry and Behavioral Sciences, Duke University Medical Center, Box 102382, Durham, NC 27710 USA, Tel: 919-684-3401; Fax: 919-681-7950; E-mail: courtney.thornburg@gmail.com

Received June 07, 2013; Accepted July 15, 2013; Published July 18, 2013

Citation: Boateng L, Puffer E, Allen T, Bonner M, Thornburg CD (2013) Adherence to Secondary Stroke Prevention in Children with Sickle Cell Anemia: Family and Child Perspectives. J Blood Disorders Transf 4:148. doi:10.4172/21559864.1000148

Copyright: (c) 2013 Boateng L, et al. This is an open-access article distributed under the terms of the Creative Commons Attribution License, which permits unrestricted use, distribution, and reproduction in any medium, provided the original author and source are credited. 


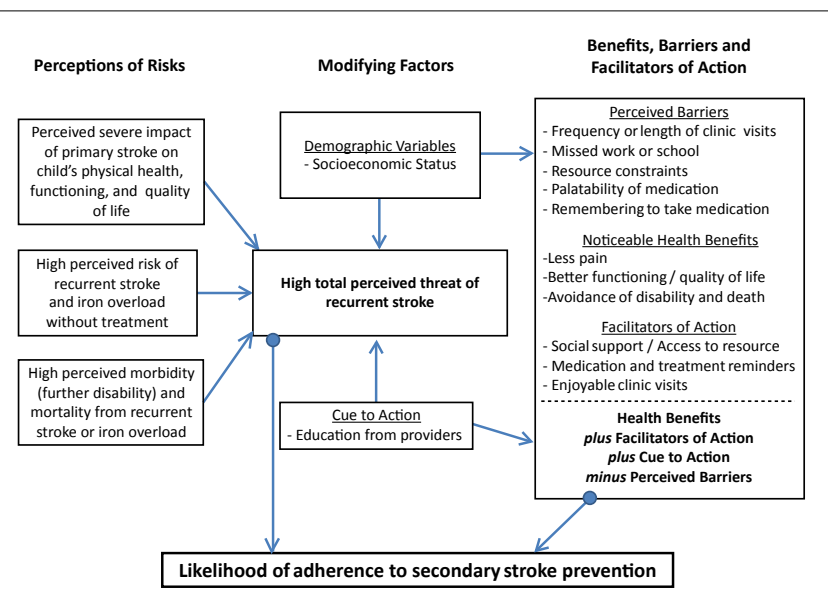

Figure 1: Health Brief Model.

that recurrent stroke should be avoided and that the treatment will be effective in stroke prevention. The likelihood of adherence is then modified by cues to action and barriers. We designed this study to use the HBM to evaluate disease and treatment burden, to determine treatment preferences, and to identify and compare facilitators and barriers to secondary stroke prevention therapies.

\section{Methods}

Participants were a convenience sample of children followed by the Duke Pediatric Sickle Cell Program and their caregivers. Childcaregiver pairs were eligible if the child was 3 years of age or older, had SCA, and had suffered an overt or silent stroke. Of all children followed in the clinic, 15 were eligible and 14 participated. Demographic data were reported by caregivers, and medical records were used to determine the subject's age, gender, type of stroke, time since stroke, therapy for secondary stroke prevention, therapy for transfusionrelated iron overload, number of clinic visits within the past year, education status, and any neurocognitive evaluations within two years of the study. Transfusions are typically administered every 4-5 weeks or 10-12 times per year. Hydroxyurea visits are scheduled monthly until the maximum tolerated dose is achieved and then every 2-3 months.

A pediatric hematologist (C.T.) designed the qualitative interview guides in collaboration with clinical psychologists (E.P., M.B.). Interview guides were tailored to children and caregivers, current treatments (transfusion versus hydroxyl urea), and for child age range. The interview guide included questions about perceptions of risk and consequences of secondary stroke and of iron overload (e.g., what do you think would happen to your child in the long-term if she did not receive treatment?), and facilitators and barriers to therapy adherence (e.g., Describe how you fit the transfusion/hydroxyl urea appointments into your life?) (Table 1). A clinical psychologist (E.P.) trained in qualitative interviewing conducted the interviews during regularly scheduled clinic visits. Interviews lasted between 15 and 60 minutes, with the shorter interviews given by younger children. Informed consent was obtained from the caregivers and assent from the children prior to participation. The Institutional Review Board of Duke University Medical Center approved the study.

Coding and analysis was conducted by two investigators (E.P. and C.T.) following a modified grounded theory approach. The first step was open coding in which two investigators (E.P. and C.T.) reviewed all of the data to identify themes. Themes from both coders were combined and guided the second step of selective coding by three investigators. After independent coding, investigators discussed results and reached consensus. The final stage was theoretical coding in which one investigator (E.P.) coded the data by the broader conceptual components of the HBM.

\section{Results}

Participants were 14 female care giver sand 12 children; two were not interviewed because they were under six years old. All subjects had SCA with hemoglobin SS genotype. The median child age was 5.8 years, range 0.5-13.4 years. There were a total of 84.3 patient-years of experience with secondary stroke prevention. Of the patients who had been followed at Duke University Medical Center on their current therapy for at least 1 year prior to study participation, 4 subjects in the hydroxyl urea group had a median of 4 clinic visits (range 4-9) in the past year, and 6 subjects in the transfusion group had a median of 12.5 clinic visits (range 12-15) within the past year. Other demographic data and treatment characteristics of the participants are presented in Table 2.

Nine subjects had neurocognitive evaluations within two years of the study with a median Full Scale IQ of 77, well below average (range 56-101). All subjects had some impairment in school or behavioral functioning.

\section{Perceived Risks}

Participants clearly recognized the severity of stroke and the

\begin{tabular}{|c|c|}
\hline Introductory Questions & $\begin{array}{l}\text { What is the impact of sickle cell disease on daily } \\
\text { life for your child and for your family? } \\
\text { How do you think the stroke impacted your child's } \\
\text { life? }\end{array}$ \\
\hline $\begin{array}{l}\text { Perception of Risk of } \\
\text { Recurrent Stroke }\end{array}$ & $\begin{array}{l}\text { What do understand about the risk of your child } \\
\text { having another stroke? } \\
\text { In your own words, what do you think would } \\
\text { happen to your child in the long term if he/she } \\
\text { didn't receive treatment? Do you think your child } \\
\text { is at higher risk for stroke if he/she misses some } \\
\text { treatment? }\end{array}$ \\
\hline $\begin{array}{l}\text { Perception of Benefits of } \\
\text { Stroke Prevention }\end{array}$ & $\begin{array}{l}\text { Can you describe how stroke prevention makes } \\
\text { your child's life better? Can you give a specific } \\
\text { example? }\end{array}$ \\
\hline Barriers and Facilitators & $\begin{array}{l}\text { Can you describe how you fit the transfusion/ } \\
\text { hydroxyurea appointments into your life? } \\
\text { From time to time, everyone has difficulty making } \\
\text { it to appointments? What makes it difficult to } \\
\text { make it to appointments? } \\
\text { What helps you to make sure your child gets his/ } \\
\text { her transfusion/hydroxyurea? } \\
\text { How confident are you in your ability to follow the } \\
\text { treatment recommended by your child's doctor? }\end{array}$ \\
\hline $\begin{array}{l}\text { Transfusion versus } \\
\text { Hydroxyurea }\end{array}$ & $\begin{array}{l}\text { What are the benefits of taking hydroxyurea } \\
\text { compared to transfusion? } \\
\text { What are the disadvantages of taking } \\
\text { hydroxyurea compared to transfusion? }\end{array}$ \\
\hline
\end{tabular}

*Age appropriate questions were used for the pediatric subjects.

Table 1: Examples of parent* interview questions related to primary stroke prevention. 
Citation: Boateng L, Puffer E, Allen T, Bonner M, Thornburg CD (2013) Adherence to Secondary Stroke Prevention in Children with Sickle Cell Anemia: Family and Child Perspectives. J Blood Disorders Transf 4:148. doi:10.4172/2155-9864.1000148

Page 3 of 7

multiple negative effects of the original stroke. They discussed serious impacts on school functioning, attention, personality, participation in sports, and overall quality of life. One child said, "I would have been able to play sports, walk right, and go outside when I wanted..." Some caregivers described personality changes and decreases in physical and social activities. "I think it has made him more introverted....instead of just saying or doing something, for fear of being laughed at, he won't do anything. He will just be quiet when he is with a group of other children. That is something that was left over from the stroke." - Caregiver (hydroxyurea).

Likewise, all caregivers agreed that their child was at risk of recurrent stroke and expressed worries about the consequences. Some caregivers focused on the potential functional impact, and several others mentioned the possibility of death. These fears were closely related to their high motivation for adherence, as many caregivers attributed their child's survival directly to the treatment. "If he had another stroke he probably wouldn't really have any more use of his arms and legs. He has a real weakness in his right side right now... he'd probably be in a wheelchair."- Caregiver(transfusions).

"If he wasn't on the treatment, he probably would have had a major [stroke]. He probably wouldn't even be here right now." Caregiver(transfusions).

"It's terribly important. To me there is nothing worse than the thought of a child having anything wrong with them...Anything that can stop it in its track and make a child have a normal or semi-normal quality of life.... God bless whoever came up with hydroxyurea...It is keeping him stroke free... We do exactly what the doctors are telling us to do. If he doesn't take his medicines in the morning, I am at the school with this medicine pulling him out of class...It is keeping him alive. And life is what it is all about." -Caregiver (hydroxyurea).

Participants also expressed concerns about iron overload and were well versed in the risks. This knowledge motivated their desire to adhere with oral iron chelation. "Sometimes I forget to take medicine. I know that it is important for me to take it or my iron will go up and go straight to my heart." - Child (transfusions).

Another child noted risks associated with iron overload before he switched to hydroxyurea. "If I wasn't on hydroxyurea, then that means that I probably would still be having transfusions. That would be an even bigger risk, because even when they first took me off I had a bad iron overload...it would be like just more risk of damage to my organs." - Child (hydroxyurea).

\section{Perceived Barriers to Adherence}

Barriers to adherence included frequency and length of clinic visits, missed school and work due to these visits, and lack of financial and material resources. To attend visits, children frequently miss a full day of school. The accompanying caregiver often misses a day of work or must work additional hours that do not fit within their typical routine. In order to avoid multiple missed days of school and work, some parents preferred multiple appointments scheduled on the same day but reported that the clinic cannot always coordinate the schedule.

"I try to not to let her miss a whole lot of days...If she has two appointments scheduled, I try to make sure both appointments are on the same day.... It's hard because some doctors want you in their office at certain times...it's a decision that you have to sit and think about to make."- Caregiver (hydroxyurea).

"So at work I'll always schedule on the day before he has to come in...I tell them I'm going to be late coming into work, or I bring him after work...I worked last night so I could have off." - Caregiver(transfusions).

Caregivers noted a variety of resource-related challenges including loss of income, lack of transportation and need for childcare. A parent of a child on transfusions said, "Sometimes I just can't work, and it takes money away from the family." Another described dependence on others, saying "I rely on [others for] transportation. Sometimes that is an issue...I don't have a way to get here." One caregiver described how her own medical problems interfere; she explained, "I'm disabled myself, and if I'm hurting I can't bring him because he's not able to drive yet." Further, many caregivers described how difficult it is to make arrangements for their other children. One parent said, "The most [challenging] was babysitting for the other children. I remember one time I kept all of the kids out of school and brought them all so that she could get her transfusions.'

Patients reported far fewer barriers related to taking hydroxyurea, as clinic visits are often shorter and can be less frequent after patients reach their maximum tolerated dose. The most common barrier they reported was remembering to take the medication. As one child said, "[When I am] watching TV, talking on the phone, typing on the computer - then I just forget.". For iron chelation, the major barrier to adherence was the bad taste of the medication. This led to children refusing to take the medication, creating parent-child conflict. A

\begin{tabular}{|c|c|c|c|c|}
\hline $\begin{array}{c}\text { Age } \\
\text { (years) }\end{array}$ & Gender & $\begin{array}{c}\text { Time since initial therapy } \\
\text { (years) }\end{array}$ & Current therapy & Prior use of alternative \\
\hline 3 & $\mathrm{~F}$ & 0.5 & Transfusion/Oral chelation & No \\
\hline 5 & $\mathrm{M}$ & 2.3 & Transfusion/Oral chelation & No \\
\hline 10 & M & 2.8 & Transfusion/Oral chelation & Hydroxyurea \\
\hline 12 & M & 1.2 & Transfusion/Oral chelation & Hydroxyurea \\
\hline 12 & $\mathrm{~F}$ & 5 & Transfusion/Oral chelation & No \\
\hline 13 & M & 7.2 & Transfusion/Oral chelation & Hydroxyurea/phlebotomy \\
\hline 14 & M & 13.4 & Pheresis & Hydroxyurea/phlebotomy \\
\hline 16 & M & 10.2 & Pheresis & Hydroxyurea/phlebotomy \\
\hline 16 & $\mathrm{~F}$ & 2.4 & Pheresis/Oral chelation & Hydroxyurea/phlebotomy \\
\hline 8 & M & 3.7 & Hydroxyurea & Transfusion/chelation/phlebotomy \\
\hline 12 & $\mathrm{M}$ & 6.6 & Hydroxyurea & Transfusion/chelation/phlebotomy \\
\hline 13 & M & 12.7 & Hydroxyurea & Transfusion/chelation/phlebotomy \\
\hline 14 & $\mathrm{~F}$ & 7.9 & Hydroxyurea & No \\
\hline 17 & M & 8.4 & Hydroxyurea & Transfusion/chelation/phlebotomy \\
\hline
\end{tabular}

Table 2: Demographic and treatment characteristics 
caregiver of a child on transfusions and deferasirox described,_ "It is hard work just getting her to take the [oral iron chelator]. She says it is nasty. We try to find new ways to allow her to take [it]. We know this is important to her well-being... Before she wasn't taking it. She was saying she was taking it, but she was throwing it in the garbage. Now we watch her take it or we have her sister watch."

\section{Promoting Action: Cues and Facilitators}

Education from the clinic team was the primary cue to action for participants. They were receiving clear and consistent information about the treatments, as evidenced both by their direct reports of this and by their demonstrated knowledge when discussing the therapies in the interviews. Their other responses related to factors that promoted treatment did not, however, fit clearly into the HBM category of "cues to action." Rather, an important distinction emerged between the "cue to action"-education-and factors that influenced whether they were able to actually respond to these cues and follow through with the behavior. We thus decided to adapt the model to include "facilitators of action." These included: experiencing noticeable health benefits of treatment, strong social support systems, medication reminders, and positive clinic experiences.

\section{Noticeable health benefits}

Caregivers noted benefits of transfusions other than stroke prevention including reduction in pain, fewer hospitalizations, and greater quality of life. "I think it causes him to be more of a normal person...not only [prevents] the strokes, but even having like sickle cell crisis or even just day-to-day feeling bad." - Caregiver (transfusions).

"Since he has been having the transfusions he hasn't had any crisis. In past experience, his crises have been long-lasting and painful... There is not much can do for it. That is a bad feeling." - Caregiver (transfusions).

Similar benefits were reported by caregivers of children on hydroxyl urea who noted reductions in pain and increased energy and activity. One child said, "[hydroxyl urea] keeps me at a steady pace. It keeps my energy flowing, keeps my blood flowing." Similarly, a caregiver reported that her child "started doing more. She started being active. It did a lot. I mean it's no one specific thing it has done; it's everything."

\section{Social support}

Many caregivers reported meaningful support from family members and friends, primarily by providing transportation or childcare. A parent of a child on transfusions said, "It is a matter of juggling. It literally takes a village to take care of children." Another said, "Everyone is pretty flexible. If I can't come, them my husband could come. If you don't have team support then it becomes a little more tedious." Some families also expressed feeling connected with the medical team in terms of shared responsibility for the child's care. When asked what advice she would give to other families, this caregiver said, "Families have got to understand and buy into that they are part of the medical team."

\section{Medication reminders}

Some parents described themselves as responsible for ensuring that their child takes their medication, while parents of older children more commonly reported efforts to transfer the responsibility to their adolescent. Most often, however, caregivers described sharing responsibility with their child. One caregiver spoke about her personal responsibility, as well as that of other caregivers in her situation, saying: They [parents] need to keep the prescriptions filled...YYu've got to make sure they take their medication. I don't care if they are 12 years old. Kids are kids. They are not going to want to take their medication. You've got to do it." - Caregiver (transfusions).

One adolescent described how she remembers her hydroxyurea independently, saying, "I remember on my own. The only help I have if I'm not looking at the clock, is that my cell phone goes off to tell me that it's time for me to take my medicine."

\section{Enjoyable clinic experiences}

Although some children mentioned disliking needles and shots, many enjoyed their appointments due to activities and rewards in the clinic. Some also welcomed the break from attending school. One young child on transfusions said, "I get to play games. I get to do art, color." Another described entertainment and social benefits, saying "I am able to play the games on PlayStation and Xbox. Some of my old friends from camp are here."

\section{Patient Preferences between Hydroxy urea and Transfusion}

Most patients had experience with both transfusions and hydroxyl urea. Patients who had been on transfusions and were currently on hydroxyl urea preferred hydroxyl urea. Patients who had been on hydroxyl urea and were currently on transfusions indicated that hydroxyl urea would be easier, but recognized that they needed transfusions for clinical reasons. One caregiver preferred hydroxyl urea "because of getting shots and pheres is and transfusions and everything; [with hydroxyl urea] you just have to take a pill."Another caregiver also preferred hydroxyl urea, perceiving that it had equivalent health benefits without frequent, burdensome clinic visits. She said, "It's easier. It's doing the same thing as the transfusions...It's doing what it needs to do inside his body. He can still go to school; he's not missing a full day just to get a transfusion."

Likewise, children reported a preference for hydroxyl urea because of the ease and noninvasiveness relative to transfusions. One child stated, "[You] get to take two pills and get it over with. With the transfusions you have to get stuck and get blood either taken away from you or put in you." Another child compared the time required; saying she preferred hydroxyl urea "because we don't have to come back to the doctor, like every two weeks or every month... its way quicker...I mean the transfusions took like 3 hours. Hydroxy urea, I mean, it just takes like 2 seconds to swallow a pill."

\section{Discussion}

This study examined and compared adherence to secondary stroke prevention therapies through the lens of the HBM. Families understand the significant effects that stroke had on their child, the significant risk and consequences of recurrent stroke and iron overload, and the efficacy of stroke prevention and chelation strategies. The data demonstrate, however, that secondary stroke prevention places a high burden on families such that it is difficult for them to act in accordance with this knowledge and these beliefs that the treatments are effective. Adherence with therapy was within the expected range for both hydroxyl urea and transfusion. Though caregivers and children reported a preference for hydroxyl urea over transfusions alike, they perceived fewer barriers and equivalent benefits.

In the context of the HBM, parents in this study understood the risks associated with treatment non-adherence and expressed determination to follow through with medication administration and clinic visits. 
However, the barriers to these important health behaviors were clear and fell into two categories: (a) disruption of important daily activities, such as work and school, and (b) resource constraints that made clinical appointments difficult to attend. The financial impact of visits, including co-pays, transportation, and lost income, was described by almost all participants. This issue warrants special consideration given that, compared to healthy black children, black children with SCA are more likely to have government supported health insurance and to have a household income $<100 \%$ of the federal poverty level [24].

These results add to the existing literature by analyzing data from both children and caregivers of varied ages and by asking participants to compare their experiences with two secondary stroke prevention strategies; this resulted in richer data from the patient perspective than comparing different groups of patients on the different therapies. Limitations of the study included the small sample size resulting from the small number of patients served by our clinic who were eligible. This limited our ability to achieve saturation of themes and to analyze how responses and themes might vary across demographics, such as gender, age, or socioeconomic status. However, this study provides a foundation for future studies with larger samples that could examine these patterns. Future studies could also compare adherence between different patient populations managed with chronic transfusions to understand which barriers to therapy are unique to patients with SCA and which are similar across along conditions.

As our understanding of adherence improves, it is important to develop and evaluate interventions to remove barriers and increase facilitators. We describe some potential approaches here. While there are currently no evidence-based interventions to improve adherence to secondary stroke prevention, it is promising to note that the sickle cell community is beginning to take action to improve medication adherence as part of the "Working to Improve Sickle Cell Healthcare" initiative funded through Health Resources and Services Administration [25].

Improved assessment procedures may be a first step to improving adherence, with standardized procedures for clinicians to conduct an individualized assessment of barriers and facilitators when making treatment decisions for patients. Crosby et al. have described a "Take Charge Program" which integrates web-based technology to assess hydroxyl urea adherence and clinical outcomes in pediatric SCA [10]. This could lead to a pre-determined cascade of services to mitigate problems from the beginning. In part, this may require dedicated personnel in the clinic, such as social workers, who can facilitate acquisition of resources. As examples, social workers can help caregivers with Family Medical Leave Act paper work; support parents as they work with their child's school to develop accommodations to attenuate the impact of missed days; and identify ways to access statefunded transportation. Further, dedicated personnel and clinicians can strategize with families to identify social supports [26,27]. In addition, evidence-based family-level interventions, which address family dynamics and stressors (related and unrelated to the chronic illness) that interfere with medical adherence, could be implemented. These interventions, which have been tested in pediatric diabetes, renal transplant, and cystic fibrosis [28-31], help identify ecological supports, reduce stress, and increase treatment adherence.

To maximize adherence to oral medications, accessibility is paramount. For hydroxyl urea, the capsule form is widely available, but the liquid formulation must be compounded which adds to the cost, and access is limited to hospital and specialty pharmacies. Teaching children to swallow pills is one concrete solution. If this is not possible, the liquid formulation may be mailed to the home, or local compounding pharmacies can be identified. For iron chelation, research is ongoing to determine if deferasirox can be taken with a wider variety of liquids or foods to improve palatability (NCT 00845871).

Education should also be integrated explicitly into clinic visits. Indeed, the vast majority of evidence-based interventions in pediatric chronic illness include relevant education for families. In the context of the current study and the HBM, education was a primary cue to action, and facilitated families' motivation to adhere to secondary stroke prevention regimens. Further, perceived safety and efficacy of therapies have been shown to be important factors affecting treatment preference among parents and their children with SCA [32]. Education should be tailored to the family's baseline knowledge, health literacy and experience. When initiating secondary stroke prevention, families should be aware of all components of care, including the exact frequency of visits required. For medications, education should include instructions for medication administration, reasons for medicine, relationship between medicine and illness, and how to obtain medicine [33]. Reviewing adherence using directed questions and clinical data can also be effective, particularly when patients are educated about the meaning of test results; for example, blood smears can be used to demonstrate effects of hydroxyurea $[34,35]$, and patients can be rewarded for doing their part to achieve positive results.

Education is insufficient to improve adherence. Many evidencebased interventions have focused on a combination of education and behavioral approaches for children with chronic medical illness [3639]. In the context of secondary stroke prevention, evidence-based behavioral strategies may be useful to help parents and children organize the at-home medical regimen and clinic appointments through paper calendars or mobile health technologies. Indeed, with improvement in technology and universal access to cell phones, electronic devices may be used to provide education, monitor therapy and send reminder messages for medication doses, refills and clinic visits [10,40-43]. In addition, behavioral strategies, such as offering small rewards (e.g., small toys, or special privileges), can incentivize children to take their medications and attend clinic visits [44-46].

More recently, there has also been compelling theoretical and empirical support for the use of motivational interviewing as a strategy to improve treatment outcomes in a variety of patient groups, including individuals with HIV, pediatric diabetes, and cystic fibrosis [47-50]. This empirically-supported, patient-centered method to counseling aims to increase an individual's intrinsic motivation for, and commitment to, health behavior. For secondary stroke prevention, the target of motivational interviewing might vary depending on the precise barrier with which a family is struggling, making it particularly useful and adaptable. For instance, a motivational interviewing protocol could help better engage autonomous adolescents in their treatment and facilitate their awareness of adaptive versus maladaptive health behavior. Motivational interviewing could also be used to increase a caregiver's commitment to their child's medical regimen, and in turn, their motivation to seek out the financial assistance needed to pay for clinic visits or medication. In the latter example, motivational interviewing may have the capacity to attenuate the perceived-impact of resource barriers or disrupted activities, which were two of the primary concerns identified by families in this study. Healthcare providers who are trained in motivational interviewing can deliver this intervention over the phone or in-person, in brief (e.g., 15-minute) or extended intervals (e.g., 60-minutes) [51]. Although research is still needed to assess this methodology for patients with SCA, the flexibility of this approach may make it particularly feasible for busy clinics trying to address the multiple barriers to secondary stroke prevention. 
Citation: Boateng L, Puffer E, Allen T, Bonner M, Thornburg CD (2013) Adherence to Secondary Stroke Prevention in Children with Sickle Cell Anemia: Family and Child Perspectives. J Blood Disorders Transf 4:148. doi:10.4172/2155-9864.1000148

In summary, secondary stroke prevention requires a large investment of effort and resources from families. Ultimately, the community of providers and families should collaborate to develop a set of creative strategies to address barriers and optimize adherence with hydroxyurea, transfusion therapy and iron chelation at the time of prescription.

\section{Acknowledgements}

The authors thank the children and their caregivers for participation in the study. The authors thank Brittany Herzberg, Jeremy Whitley, and Kathryn Cochran for interview transcription. The study was supported by a Comprehensive Sickle Cell Center Investigator Research Supplement U54-HL070769 (C.T.)

\section{References}

1. Ohene-Frempong K, Weiner SJ, Sleeper LA, Miller ST, Embury S, et al. (1998) Cerebrovascular accidents in sickle cell disease: rates and risk factors. Blood 91: $288-294$

2. Pegelow CH, Adams RJ, McKie V, Abboud M, Berman B, et al. (1995) Risk of recurrent stroke in patients with sickle cell disease treated with erythrocyte transfusions. J Pediatr 126: 896-899.

3. Scothorn DJ, Price C, Schwartz D, Terrill C, Buchanan GR, et al. (2002) Risk of recurrent stroke in children with sickle cell disease receiving blood transfusion therapy for at least five years after initial stroke. J Pediatr 140: 348-354.

4. Ware RE, Zimmerman SA, Sylvestre PB, Mortier NA, Davis JS, et al. (2004) Prevention of secondary stroke and resolution of transfusional iron overload in children with sickle cell anemia using hydroxyurea and phlebotomy. J Pediatr 145: 346-352.

5. Ware RE, Steinberg MH, Kinney TR (1995) Hydroxyurea: an alternative to transfusion therapy for stroke in sickle cell anemia. Am J Hematol 50: 140-143.

6. Ware RE, Zimmerman SA, Schultz WH (1999) Hydroxyurea as an alternative to blood transfusions for the prevention of recurrent stroke in children with sickle cell disease. Blood 94: 3022-3026.

7. Greenway A, Ware RE, Thornburg CD (2011) Long-term results using hydroxyurea/phlebotomy for reducing secondary stroke risk in children with sickle cell anemia and iron overload. Am J Hematol 86: 357-361.

8. Ware RE, Zimmerman SA, Schultz WH (1999) Hydroxyurea as an alternative to blood transfusions for the prevention of recurrent stroke in children with sickle cell disease. Blood 94: 3022-3026.

9. Thornburg CD, Calatroni A, Telen M, Kemper AR (2010) Adherence to hydroxyurea therapy in children with sickle cell anemia. J Pediatr 156: 415-419.

10. Crosby LE, Barach I, McGrady ME, Kalinyak KA, Eastin AR, et al. (2012) Integrating interactive web-based technology to assess adherence and clinical outcomes in pediatric sickle cell disease. Anemia 2012: 492428

11. Candrilli SD, O'Brien SH, Ware RE, Nahata MC, Seiber EE, et al. (2011) Hydroxyurea adherence and associated outcomes among Medicaid enrollees with sickle cell disease. Am J Hematol 86: 273-277.

12. Patel NG, Lindsey T, Strunk RC, DeBaun MR (2010) Prevalence of daily medication adherence among children with sickle cell disease: a 1-year retrospective cohort analysis. Pediatr Blood Cancer 55: 554-556.

13. Brandow AM, Jirovec DL, Panepinto JA (2010) Hydroxyurea in children with sickle cell disease: practice patterns and barriers to utilization. Am J Hematol 85: 611-613

14. Oyeku SO, Driscoll MC, Cohen HW, Trachtman R, Pashankar F, et al. (2013) Parental and other factors associated with hydroxyurea use for pediatric sickle cell disease. Pediatr Blood Cancer 60: 653-658.

15. Brandow AM, Panepinto JA (2010) Hydroxyurea use in sickle cell disease: the battle with low prescription rates, poor patient compliance and fears of toxicities. Expert Rev Hematol 3: 255-260.

16. Haywood C Jr, Beach MC, Bediako S, Carroll CP, Lattimer L, et al. (2011) Examining the characteristics and beliefs of hydroxyurea users and nonusers among adults with sickle cell disease. Am J Hematol 86: 85-87.

17. Brawley OW, Cornelius LJ, Edwards LR, Gamble VN, Green BL, et al. (2008) National Institutes of Health Consensus Development Conference statement hydroxyurea treatment for sickle cell disease. Ann Intern Med 148: 932-938.
18. Ware RE, Zimmerman SA, Sylvestre PB, Mortier NA, Davis JS, et al. (2004) Prevention of secondary stroke and resolution of transfusional iron overload in children with sickle cell anemia using hydroxyurea and phlebotomy. J Pediatr 145: 346-352.

19. Aygun B, McMurray MA, Schultz WH, Kwiatkowski JL, Hilliard L, et al. (2009) Chronic transfusion practice for children with sickle cell anaemia and stroke. $\mathrm{Br}$ J Haematol 145: 524-528.

20. Raphael JL, Bernhardt MB, Mahoney DH, Mueller BU (2009) Oral iron chelation and the treatment of iron overload in a pediatric hematology center. Pediatr Blood Cancer 52: 616-620.

21. Porter JB, Evangeli M, El-Beshlawy A (2011) Challenges of adherence and persistence with iron chelation therapy. Int J Hematol 94: 453-460.

22. Mednick LM, Braunstein J, Neufeld E (2010) Oral chelation: should it be used with young children? Pediatr Blood Cancer 55: 603-605.

23. Becker MH, Maiman LA, Kirscht JP, Haefner DP, Drachman RH, et al (1979) Patient perceptions and compliance: recent studies of the health belief model. In: Haynes RB, Taylor DW, Sackett DL, editors. Compliance in health care. The Johns Hopkins University Press, Baltimore.

24. Boulet SL, Yanni EA, Creary MS, OIney RS (2010) Health status and healthcare use in a national sample of children with sickle cell disease. Am J Prev Med 38 : S528-535.

25. Working to Improve Sickle Cell Healthcare. Accessed: March 15, 2013.

26. Belgrave FZ, Lewis DM (1994) The role of social support in compliance and other health behaviors for African Americans with chronic illnesses. $J$ Health Soc Policy 5: 55-68.

27. Sawyer SM, Aroni RA (2003) Sticky issue of adherence. J Paediatr Child Health 39: $2-5$.

28. Anderson BJ, Brackett J, Ho J, Laffel L (2000) An intervention to promote famliy teamwork in diabetes management tasks: relationships among parental involvement, adherence to blood glucose monitoring, and glycemic cotrol in young adolescents with type I diabetes. In: Drotar D, ed. Promoting adherence to medical treatment in chronic childhood illness: concepts, motherds, and interventions. Lawrence Erlbaum Associates, Inc, Mahwah, NJ.

29. Fennell RS, Foulkes LM, Boggs SR (1994) Family-based program to promote medication compliance in renal transplant children. Transplant Proc 26: 102 103

30. Quittner AL, Drotar D, levers-Landis C, Seidner D, Slocum N, et al (2000) Adherence to medical treatments in adolescents with cystic fibrosis: The development and evaluation of family-based interventions. In: Drotar D, ed. Promoting adherence to medical treatment in chronic childhood illness: concepts, motherds, and interventions. Lawrence Erlbaum Associates, Inc Mahwah, NJ:

31. Romi T, Kowen G (2006) Multidisciplinary family-based intervention in the treatment of diabetic adolescents with an eating disorder. Journal of Family Psychotherapy 17: 21-36.

32. Hankins J, Hinds P, Day S, Carroll Y, Li CS, et al. (2007) Therapy preference and decision-making among patients with severe sickle cell anemia and their families. Pediatr Blood Cancer 48: 705-710.

33. Bosworth HB, Granger BB, Mendys P, Brindis R, Burkholder R, et al. (2011) Medication adherence: a call for action. Am Heart J 162: 412-424.

34. Ware RE (2010) How I use hydroxyurea to treat young patients with sickle cell anemia. Blood 115: 5300-5311.

35. Strouse JJ, Heeney MM (2012) Hydroxyurea for the treatment of sickle cell disease: efficacy, barriers, toxicity, and management in children. Pediatr Blood Cancer 59: 365-371.

36. Peterson AM, Takiya L, Finley R (2003) Meta-analysis of trials of interventions to improve medication adherence. Am J Health Syst Pharm 60: 657-665.

37. De Bleser L, Matteson M, Dobbels F, Russell C, De Geest S (2009) Interventions to improve medication-adherence after transplantation: a systematic review. Transpl Int 22: 780-797.

38. Graves MM, Roberts MC, Rapoff M, Boyer A (2010) The efficacy of adherence interventions for chronically ill children: a meta-analytic review. J Pediatr Psychol 35: 368-382.

39. Kahana S, Drotar D, Frazier T (2008) Meta-analysis of psychological 
Citation: Boateng L, Puffer E, Allen T, Bonner M, Thornburg CD (2013) Adherence to Secondary Stroke Prevention in Children with Sickle Cell Anemia: Family and Child Perspectives. J Blood Disorders Transf 4:148. doi:10.4172/2155-9864.1000148

interventions to promote adherence to treatment in pediatric chronic health conditions. J Pediatr Psychol 33: 590-611.

40. Derose SF, Green K, Marrett E, Tunceli K, Cheetham TC, et al. (2013) Automated outreach to increase primary adherence to cholesterol-lowering medications. JAMA Intern Med 173: 38-43.

41. Ownby RL, Waldrop-Valverde D, Caballero J, Jacobs RJ (2012) Baseline medication adherence and response to an electronically delivered health literacy intervention targeting adherence. Neurobehav HIV Med 4: 113-121.

42. Vervloet M, van Dijk L, Santen-Reestman J, van Vlijmen B, van Wingerden $P$, et al. (2012) SMS reminders improve adherence to oral medication in type 2 diabetes patients who are real time electronically monitored. Int J Med Inform 81: 594-604.

43. Vervloet M, Linn AJ, van Weert JC, de Bakker DH, Bouvy ML, et al. (2012) The effectiveness of interventions using electronic reminders to improve adherence to chronic medication: a systematic review of the literature. J Am Med Inform Assoc 19: 696-704.

44. Burkhart PV, Rayens MK, Oakley MG, Abshire DA, Zhang M (2007) Testing an intervention to promote children's adherence to asthma self-management. J Nurs Scholarsh 39: 133-140.
45. Carton JS Schweitzer JB (1996) Use of a token economy to increase compliance during hemodialysis. J Appl Behav Anal 29: 111-113.

46. Stark LJ, Bowen AM, Tyc VL, Evans S, Passero MA (1990) A behaviora approach to increasing calorie consumption in children with cystic fibrosis. J Pediatr Psychol 15: 309-326.

47. Channon S, Smith VJ, Gregory JW (2003) A pilot study of motivational interviewing in adolescents with diabetes. Arch Dis Child 88: 680-683.

48. Parsons JT, Rosof E, Punzalan JC, Di Maria L (2005) Integration of motivationa interviewing and cognitive behavioral therapy to improve HIV medication adherence and reduce substance use among HIV-positive men and women: results of a pilot project. AIDS Patient Care STDS 19: 31-39.

49. Duff AJ, Latchford GJ (2010) Motivational interviewing for adherence problems in cystic fibrosis. Pediatr Pulmonol 45: 211-220.

50. Erickson SJ, Gerstle M, Feldstein SW (2005) Brief interventions and motivationa interviewing with children, adolescents, and their parents in pediatric health care settings: a review. Arch Pediatr Adolesc Med 159: 1173-1180.

51. Rubak S, Sandbaek A, Lauritzen T, Christensen B (2005) Motivationa interviewing: a systematic review and meta-analysis. Br J Gen Pract 55: 305312 